\title{
CORRELATION OF CLINIC-HISTOPATHOLOGICAL FINDINGS IN DIFFERENT FORMS OF APPENDICITIS
}

\author{
Yashwanth C. $N^{1}$, Dileep C. $N^{2}$
}

${ }^{1}$ Assistant Professor, Department of Surgery, KMC, Palakkad.

${ }^{2}$ Resident, Department of Emergency Medicine, SSIMS, Davanagere.

\begin{tabular}{l} 
ABSTRACT \\
\hline BACKGROUND \\
The existence of recurrent and chronic appendicitis is still doubted by many. This study is intended to study correlation of clinical \\
findings, operative findings and the histopathological findings among the different $\{$ (acute and chronic (recurrent) $\}$ forms of \\
appendicitis, to study the recurrence of appendicitis in patients with acute appendicitis who were treated non-surgically at first \\
presentation, to compare the operative and histopathological findings in acute and chronic (recurrent) forms of appendicitis.
\end{tabular}

\section{MATERIALS AND METHODS}

A total of 100 consecutive cases of suspected appendicitis who were admitted, investigated and treated were taken up for the study. Data related to the objectives of the study were collected. After detailed examination and investigations the clinical, sonological, operative and histopathological findings were correlated.

\section{RESULTS}

1. Age group of patients ranged from 5 yrs. to $60 \mathrm{yrs}$. with a mean age of $25.35 \mathrm{yrs}$. with an S. D. of $9.3 \mathrm{yrs}$.

2. The sex distribution was almost equal with $49 \%$ males and $51 \%$ females.

3. Maximum occurrence of appendicitis was in the age group of 21 - $30 \mathrm{yrs}$.

4. There was history suggestive of acute appendicitis in the past, which was managed non-surgically was present in $81 \%$ of the patients.

5. Right iliac fossa tenderness was the predominant sign present in $100 \%$ of patients. It was mildly tender in $55 \%$ of patients suggestive of a chronic (recurrent) form and moderate-to-severely tender in $45 \%$ of patients suggestive of an acute form of appendicitis.

6. Per-operatively, the appendix appeared non-inflamed in $57 \%$ of patients suggestive of a chronic (recurrent) form and inflamed in $43 \%$ of patients suggestive of an acute form of appendicitis.

7. The histopathological studies revealed chronic inflammatory cells in $63 \%$ of the resected specimens, suggestive of chronic appendicitis and acute inflammatory cells in $37 \%$ of the specimens suggestive of acute appendicitis.

\section{CONCLUSION}

We conclude that the Clinical findings, Operative findings and the Histopathological findings correlate with one another (P < 0.001$)$. The surgeon's clinical and operative findings have specificity of around $87.30 \%$ and $90.47 \%$ respectively. Hence, the diagnostic accuracy of the surgeon is directly dependent on the surgeon's expertise and there is no substitution for an experienced surgeon's judgement.

\section{KEYWORDS}

Acute Appendicitis, Chronic Appendicitis, Recurrent Appendicitis, Recurrence, Operative Findings, Histopathological Findings.

HOW TO CITE THIS ARTICLE: Yashwanth CN, Dileep CN. Correlation of clinic-histopathological findings in different forms of appendicitis. J. Evolution Med. Dent. Sci. 2016;5(92):6824-6828, DOI: 10.14260/Jemds/2016/1544

\section{BACKGROUND}

Appendicitis is still the most common reason for abdominal surgery. The diagnosis may be wrongly made or initially overlooked in case of acute appendicitis. The first error leads to an unnecessary operation and the second to delay. ${ }^{1}$

Acute appendicitis, perhaps the most common surgically correctable cause of abdominal pain: the diagnosis of which remains difficult in many instances. Arriving at the correct diagnosis is essential, however, as a delay may allow

Financial or Other, Competing Interest: None.

Submission 28-10-2016, Peer Review 09-11-2016,

Acceptance 11-11-2016, Published 17-11-2016.

Corresponding Author:

Dr. Yashwanth C. N,

D. No. 788/3, Mathru Shree Nilaya,

Saraswathinagar, Davanagere-577004

Karnataka.

E-mail: dryashwanthcn@yahoo.co.in

DOI: $10.14260 /$ jemds $/ 2016 / 1544$

(c) $\underset{\mathrm{BY}}{\mathrm{NC}} \mathrm{ND}$ progression to perforation and significantly increased morbidity and mortality. Incorrectly diagnosing a patient with appendicitis, although not catastrophic often subjects the patient to an unnecessary operation. ${ }^{2}$

The diagnosis of acute appendicitis is essentially clinical; however, a decision to operate based on clinical suspicion alone can lead to removal of a normal appendix in $15-30 \%$ cases. $^{3}$

The existence of recurrent and chronic appendicitis is still doubted by many. It has been suggested by many that perforating and non-perforating appendicitis are separate entities and that resolving episodes represents attacks of nonperforating appendicitis. A recent study of treatment of appendicitis with antibiotics alone found that 95\% resolved, but $35 \%$ represented with appendicitis within a period of 17.2 months. ${ }^{4}$ 


\section{Objectives}

1. To correlate the clinical presentation of chronic (recurrent) appendicitis with the sonological findings, operative findings and confirmed with histopathological studies.

2. To study the recurrence of appendicitis in patients with acute appendicitis who were treated non-surgically at first presentation.

3. To correlate the clinical presentation of acute appendicitis with the sonological findings, operative findings and confirmed with histopathological studies.

4. To compare the operative and histopathological findings in acute and chronic (recurrent) appendicitis.

\section{Inclusion Criteria}

1. Patients with classic history of migratory pain (which is initially in the periumbilical/epigastric region, which later localises to the right lower quadrant) with other constitutional symptoms of nausea/vomiting, anorexia, who are provisionally diagnosed as appendicitis (acute forms).

2. Patients presenting with recurrent attacks (chronic forms) of right lower abdominal pain in whom other pathologies are excluded.

3. Patients provisionally diagnosed as appendicitis and who are fit for surgery.

4. Patients who are willing for surgery.

\section{Exclusion Criteria}

1. Right lower abdominal pain due to involvement of other viscera like urinary tract infection, ureteric stone, acute gastroenteritis, Meckel's diverticulitis, disease of the urogenital systems, intussusception, Crohn's enteritis, caecal typhlitis, gynaecological disorders - pelvic inflammatory disease, ruptured ectopic, torsion of ovarian cysts.

2. Patients not fit for surgery due to various causes like appendicular mass, appendicular abscess and patients with generalised peritonitis due to appendicular perforation.

3. Patients not willing for surgery.

\section{RESULTS}

\section{Collection of Data}

A total of 100 consecutive cases of suspected appendicitis who were admitted, investigated and treated were taken for the study. After detailed examination and investigations the clinical, sonological, operative and histopathological findings were correlated.

\begin{tabular}{|c|c|c|c|}
\hline Age (Years) & No. of Cases & $\begin{array}{c}\text { No. of } \\
\text { Males }\end{array}$ & $\begin{array}{c}\text { No. of } \\
\text { Females }\end{array}$ \\
\hline $001-10$ & 3 & 1 & 2 \\
\hline $011-20$ & 26 & 15 & 11 \\
\hline $21-30$ & 51 & 24 & 27 \\
\hline $31-40$ & 15 & 8 & 7 \\
\hline $41-50$ & 4 & 1 & 3 \\
\hline $51-60$ & 1 & 0 & 1 \\
\hline Mean +/-SD & \multicolumn{3}{|c|}{$25.35+/-9.3$} \\
\hline \multicolumn{4}{|c|}{ Table 1. Depicting the Age Distribution } \\
among the Study Group \\
\hline
\end{tabular}

\section{Interpretation}

In our study, the patient's age group ranged from 5 to $60 \mathrm{yrs}$. The mean age was 25.35 yrs. with an S. D. of 9.3. The youngest was a 5-year-old male, while the oldest patient was a 60-yearold female. The highest occurrence (51\%) was seen in age group of 21 - 30 years.

\begin{tabular}{|c|c|}
\hline Sex & No. of Cases \\
\hline Male & 49 \\
\hline Female & 51 \\
\hline Table 2. Depicting the Sex Distribution \\
among the Study Group
\end{tabular}

\section{Interpretation}

Among males the highest occurrence (24\%) was seen in age group of 21 - 30 years. Among females the age group affected most (26\%) was 21 - 30 years.

\begin{tabular}{|c|c|}
\hline Pain & No. of Cases \\
\hline+ & 57 \\
\hline++ & 28 \\
\hline+++ & 15 \\
\hline \multicolumn{2}{|c|}{ Table 3. Depicting the Distribution of Pain in Right Iliac } \\
Fossa according to the Severity among the Study Group \\
\hline
\end{tabular}

\section{Interpretation}

The predominant symptom seen in the present study was pain in the right iliac fossa. Pain was present in $100 \%$ of cases, but its degree varied from mild-to-severe.

\begin{tabular}{|c|c|}
\hline Vomiting & No. of Cases \\
\hline- & 37 \\
\hline+ & 42 \\
\hline++ & 21 \\
\hline \multicolumn{2}{|c|}{ Table 4. Depicting the Frequency of } \\
Vomiting among the Study Group \\
\hline
\end{tabular}

\begin{tabular}{|c|c|}
\hline Fever & No. of Cases \\
\hline- & 43 \\
\hline+ & 47 \\
\hline++ & 10 \\
\hline \multicolumn{2}{|c|}{ Table 5. Depicting the Frequency of } \\
Fever among the Study Group
\end{tabular}

\section{Interpretation}

The $3^{\text {rd }}$ predominant symptom seen in the present study was fever. It was present in $57 \%$ of cases and absent in $43 \%$ of cases.

\begin{tabular}{|c|c|}
\hline Past History Suggestive of AA & No. of Cases \\
\hline Absent & 19 \\
\hline Present & 81 \\
\hline
\end{tabular}

\section{Table 6. Depicting the Distribution History Suggestive of} Acute Appendicitis (AA) among the Study Group

\section{Interpretation}

In our study, there were $81 \%$ of patients with history suggestive of AA and $19 \%$ of patients presented with complaints of pain abdomen for the first time.

\begin{tabular}{|c|c|}
\hline Tenderness & No. of Cases \\
\hline+ & 55 \\
\hline++ & 32 \\
\hline+++ & 13 \\
\hline \multicolumn{2}{|c|}{ Table 7. Depicting the Distribution of Tenderness in } \\
Right Iliac Fossa among the Study Group
\end{tabular}




\section{Interpretation}

The predominant sign seen in the present study was tenderness and rebound tenderness in right iliac fossa. Tenderness was present in $100 \%$ of cases.

\begin{tabular}{|c|c|}
\hline Ultrasonographic Probe Tenderness & No. of Cases \\
\hline- & 28 \\
\hline+ & 72 \\
\hline Table 8. Depicting the Frequency of Ultrasound Probe \\
Tenderness in Right Iliac Fossa among the Study Group \\
\hline
\end{tabular}

\begin{tabular}{|c|c|}
\hline OR Findings & No. of Cases \\
\hline Inflamed & 43 \\
\hline Non-inflamed & 57 \\
\hline Table 9. Depicting the Distribution of Operative \\
Findings (OR) among the Study Group \\
\hline
\end{tabular}

\section{Interpretation}

The appendix was inflamed in $43 \%$ and not inflamed in $57 \%$ of the cases.

\begin{tabular}{|c|c|}
\hline Histopathology Report & No. of Cases \\
\hline Acute & 37 \\
\hline Chronic & 63 \\
\hline Table 10. Depicting the Distribution of \\
HPR among the Study Group \\
\hline
\end{tabular}

\section{Interpretation}

Histopathology of the resected specimen was taken as the gold standard. The appendix was acutely inflamed in $37 \%$ and chronically inflamed in $63 \%$ of the cases.

\begin{tabular}{|c|c|c|c|}
\hline $\begin{array}{c}\text { Tendern } \\
\text { ess }\end{array}$ & $\begin{array}{c}\text { Ultrasound Probe } \\
\text { Tenderness } \\
\text { Present }\end{array}$ & $\begin{array}{c}\text { Ultrasound } \\
\text { Equivocal } \\
\text { (Probe } \\
\text { Tenderness } \\
\text { Absent) }\end{array}$ & Total \\
\hline+ & $28(51)$ & $27(49)$ & $55(100)$ \\
\hline++ & $31(97)$ & $1(3)$ & $32(100)$ \\
\hline+++ & $13(100)$ & 0 & $13(100)$ \\
\hline Total & $\mathbf{7 2}$ & $\mathbf{2 8}$ & \\
\hline \multicolumn{3}{|c|}{ Table 11. Depicting the Relation between Tenderness } \\
and Ultrasound Probe Tenderness Distribution among \\
the Study Group
\end{tabular}

$\mathrm{X}^{2}=27.01 ; \mathrm{P}<0.001 \mathrm{HS}$

Sensitivity $=100 \%$, Specificity $=44.44 \%$

\begin{tabular}{|c|c|c|c|}
\hline \multirow{2}{*}{$\begin{array}{c}\text { Past History } \\
\text { Suggestive of AA }\end{array}$} & \multicolumn{2}{|c|}{$\begin{array}{c}\text { Histopathology } \\
\text { Report }\end{array}$} & \multirow[t]{2}{*}{ Total } \\
\hline & Acute & Chronic & \\
\hline Absent & 18 (95) & $1(5)$ & $\begin{array}{c}19 \\
(100)\end{array}$ \\
\hline Present & 19 (23) & $62(77)$ & $\begin{array}{c}81 \\
(100)\end{array}$ \\
\hline Total & 37 & 63 & \\
\hline \multicolumn{4}{|c|}{$\begin{array}{c}\text { Table 12. Depicting the Association of Past History } \\
\text { Suggestive of AA with HPR Findings among the Study } \\
\text { Group }\end{array}$} \\
\hline
\end{tabular}

$\mathrm{X}^{2}=30.5: \mathrm{P}<0.001 \mathrm{HS}$

\begin{tabular}{|c|c|c|c|}
\hline \multirow{2}{*}{ Tenderness } & \multicolumn{2}{|c|}{ OR Findings } & \multirow{2}{*}{ Total } \\
\hline & Inflamed & Non-Inflamed & \\
\hline+ & $5(9)$ & $50(91)$ & $55(100)$ \\
\hline++ & $25(78)$ & $7(22)$ & $32(100)$ \\
\hline+++ & $13(100)$ & 0 & $13(100)$ \\
\hline Total & 43 & 57 & \\
\hline \multicolumn{4}{|c|}{ Table 13. Depicting the Relation between Tenderness } \\
\hline
\end{tabular}

$\mathrm{X}^{2}=59.14: \mathrm{P}<0.001 \mathrm{HS}$

\begin{tabular}{|c|c|c|c|}
\hline \multirow{2}{*}{ Tenderness } & \multicolumn{2}{|c|}{ Histopathology Report } & \multirow{2}{*}{ Total } \\
\cline { 2 - 3 } & Acute & Chronic & \\
\hline Positive $(++,+++)$ & $37(82)$ & $8(18)$ & $45(100)$ \\
\hline Negative $(+)$ & 0 & $55(100)$ & $55(100)$ \\
\hline Total & $\mathbf{3 7}$ & $\mathbf{6 3}$ & $\mathbf{1 0 0}$ \\
\hline
\end{tabular}

Table 14. Depicting the Association between Tenderness and Histopathological Findings among the Study Group

$\mathrm{X}^{2}=71.78: \mathrm{P}<0.001 \mathrm{HS}$

Sensitivity $=100$

Specificity $=87.30$

The patients with rebound tenderness were compared with the histopathology findings, which were considered as gold standard for the final diagnosis.

\begin{tabular}{|c|c|c|c|}
\hline \multirow{2}{*}{ OR Finding } & \multicolumn{2}{|c|}{$\begin{array}{c}\text { Histopathology } \\
\text { Report (HPR) }\end{array}$} & \multirow{2}{*}{ Total } \\
\cline { 2 - 3 } & Acute & Chronic & \\
\hline Inflamed & $37(86)$ & $6(14)$ & $43(100)$ \\
\hline Non-inflamed & 0 & $57(100)$ & $57(100)$ \\
\hline Total & $\mathbf{3 7}$ & $\mathbf{6 3}$ & \\
\hline Table 15. Depicting the Relation between Operative \\
(OR) Findings and HPR Distribution among the Study \\
Group \\
\hline
\end{tabular}

Specificity: 90.47\%; Sensitivity: 100\%. $\mathrm{X}^{2}=74.2$ : $\mathrm{P}<0.001$ HS

\section{DISCUSSION}

Appendicitis is the most common reason for abdominal surgery. The diagnosis may be wrongly made or initially overlooked in case of acute appendicitis. The first error leads to an unnecessary operation and the second to delay. ${ }^{1}$

The existence of recurrent and chronic appendicitis is still doubted by many. A recent study of treatment of appendicitis presenting with antibiotics alone found that $95 \%$ resolve, but $35 \%$ represented with appendicitis within 17.2 months. ${ }^{4}$

It is a clinical scenario in which a patient with pathologically confirmed acute appendicitis relates to one or more prior episodes of identical symptoms that resolved without surgical intervention. ${ }^{5}$

In our study, the patient's age group ranged from 5 to 60 yrs. The mean age was 25.35 yrs. with an S. D. of 9.3. The youngest was a 5-year-old male patient, while the oldest patient was a 60 -year-old female. The highest occurrence (51\%) was seen in age group of 21 - 30 years. The next age group affected (26\%) was 11 - 20 years. Overall, (77\%) of the cases were seen in the age group 11 - 30 years. 
In our study the sex distribution was with $49 \%$ males and $51 \%$ females, while in the study conducted by Addiss DG, Shaffer N, Fowler BS et al, there was a slight male-to-female predominance (M:F 1.2 to $1.3: 1) .6,7$

The predominant symptom was pain in the right iliac fossa. Though pain was present in $100 \%$ of the cases, their degree varied from mild, moderate and severe.

The 2 nd predominant symptom was vomiting, which was present in $63 \%$ of the cases.

Fever was 3rd predominant symptom present in 57\%. The history suggestive of previous acute appendicitis was present in $81 \%$ cases, who had not undergone surgical treatment at that initial setting for various reasons. The shortest history was 6 weeks and the longest history was 6 yrs. In previous studies the recurrence was estimated at $35 \%$, but the duration was within 17.2 months. ${ }^{4}$ In the present study, the duration being longer upto 6 yrs. The recurrence is being reported at $81 \%$. The past history suggestive of acute appendicitis was correlated with HPR using chi square test $\left(X^{2}=30.5 ; P<0.001\right)$ and was found to be statistically significant.

The rebound tenderness was present in $100 \%$ of the cases, but the degree varied from mild, moderate and severe tenderness in the right iliac fossa. Tenderness was mild in 57\% of the cases and they were categorised as chronic (recurrent) form of appendicitis and the moderate-to-severe tenderness present in $43 \%$ were categorised as acute form of appendicitis.

The cases were then sonologically examined and $72 \%$ of them had probe tenderness to graded compression suggestive of appendicitis. In the remaining 28\%, sonography was equivocal.

It was found in our study that the ultrasonographic findings had a sensitivity of $100 \%$ and a specificity of $44.44 \%$ as compared to the clinical diagnosis of appendicitis. This low specificity is attributed to the low specificity among chronic cases who exhibited no probe tenderness (equivocal) in $49 \%$ of the total 55 cases. Ultrasonography has the limitation of variable reliability and well known operator dependency. It appears that ultrasonogram may be most useful in excluding potential pelvic abnormality in equivocal cases. ${ }^{8}$ Furthermore, in other studies only acute cases were taken in for the study purpose, while in our study majority of the cases belonged to the chronic (recurrent) appendicitis. In one study conducted by Rao PM and Colleagues, the diagnostic accuracy of ultrasonogram was reported to range from 71 to $97 \% .{ }^{9}$

However, ultrasonogram has the limitation of variable reliability and has a well-known operator dependency and it is frequently unable to visualise the normal appendix. ${ }^{10}$

The correlation of ultrasonographic findings with the clinical findings using the chi ${ }^{2}$ test $\left(\mathrm{X}^{2}=27.01 ; \mathrm{P}<0.001\right)$ was found to be statistically significant.

The gross per-operative findings were $43 \%$ inflamed appendix suggesting an acute form, while $57 \%$ of the appendices were found to be not inflamed suggesting a chronic form of appendicitis.

The histopathological reports of these operated specimens showed acute inflammation in $37 \%$ of the cases and chronic inflammatory cell infiltrate in $63 \%$ of the cases.

The patients with rebound tenderness were correlated with the gross findings per-operatively.

Among 55 patients with mild rebound tenderness denoted by "+" in the right iliac fossa 5 patients showed associated inflammation of the appendix, while 50 patients showed no inflammation.

Among 32 patients with moderate rebound tenderness denoted by "++" in the right iliac fossa, 25 patients showed associated inflammation of the appendix, while 7 patients showed no inflammation.

The rebound tenderness was very severe in 13 patients and all showed inflammation of the appendix.

Using the $\mathrm{X}^{2}$ test, the value $\mathrm{P}<0.001$ was found to be statistically significant.

The clinical finding of rebound tenderness were compared with the histopathology findings, which were considered as gold standard for the final diagnosis.

Among 45 patients with moderate rebound tenderness denoted by "++" or severe tenderness denoted by "+++" in the right iliac fossa, 37 patients showed associated acute inflammation of the appendix, while 8 patients showed chronic inflammation of the appendix.

Among 55 patients with mild rebound tenderness denoted by " + " in the right iliac fossa, no patients showed associated acute inflammation of the appendix, while all 55 patients showed associated chronic inflammation of the appendix. It was found that the surgeon's findings had a sensitivity of $100 \%$ and a specificity of $87.30 \%$. Using the $\mathrm{X}^{2}$ test, the $\mathrm{P}$ value was found to be highly significant.

The per-operative gross appearance of the appendix was compared with the histopathology findings, which was considered as gold standard for the final diagnosis.

Among 43 patients with grossly inflamed appendix 36 patients showed associated acute inflammation of the appendix, while 6 patients showed chronic inflammation.

Among 57 patients with grossly non-inflamed appendix 0 patients showed associated acute inflammation of the appendix, while 57 patients showed chronic inflammation. It was found that the surgeon's findings had a sensitivity of $100 \%$ and a specificity of $90.47 \%$. Using the $\mathrm{X}^{2}$ test, the value $\mathrm{P}<0.001$ was found to be statistically significant.

\section{CONCLUSION}

Our study included 100 patients who were diagnosed to have appendicitis, who underwent surgical intervention. From the present study, we conclude that the Clinical findings, Operative findings and the Histopathological findings correlate with one another. The surgeon's clinical and operative findings have specificity of around $87.30 \%$ and $90.47 \%$ respectively. The surgeon was better in diagnosing the chronic forms both clinically and per-operatively $100 \%$, while the acute forms were clinically diagnosed at $86 \%$ and peroperatively at $82 \%$. Hence, the diagnostic accuracy of the surgeon is directly dependent on the surgeon's expertise and there is no substitution for an experienced surgeon's judgement. Ultrasonography of abdomen is a useful tool in avoiding negative appendicectomy rates, particularly in females and should be used in equivocal clinical findings as ultrasonography has the limitation of variable reliability and has a well-known operator dependency.

\section{REFERENCES}

1. Ooms HWA, Koumans RKJ, Ho Kang You PJ, et al. Ultrasonography in the diagnosis of acute appendicitis. Br J Surg 1991;78(3):315-8. 
2. Smink DS, Soybel DI. Appendix and appendectomy. In : Zinner MJ, Ashely SW, eds. Maingot's abdominal operations. 11 th edn. McGraw Hill 2007:589-612.

3. O' Connel PR. The vermiform appendix. In: Russell RCG, Willaims NS, Bulstrode CJK, eds. Bailey and Love's short practice of surgery. 24th edn. London: Hodder Arnold 2004:1210-11.

4. Barber MD, McLaren, Rainey JB. Recurrent appendicitis. Br J Surg 1997;84(1):110-2.

5. Sarosi GA, Turnage RH. Appendicitis. In : Feldman M, Friedman LS, Sleisenger MH, eds. Sleisenger and Fordtran's GI and liver disease, pathophysiology, diagnosis and management. $7^{\text {th }}$ edn. Pennsylvania: Saunders Elsevier 2002:2089-97.

6. Addiss DG, Shaffer N, Fowler BS, et al. The epidemiology of appendicitis and appendectomy in the United States. Am J Epidemiol 1990;132(5):910-25.
7. Korner H, Sondenaa K, Soreide JA, et al. Incidence of acute non perforated and perforated appendicitis: age-specific and sex-specific analysis. World J Surg 1997;21(3):313-7.

8. Lee SL, Walsh AJ, Ho HS. Computed tomography and ultrasonography do not improve and may delay the diagnosis and the treatment of acute appendicitis. Arch Surg 2001;136(5):556-62.

9. Wilson EB, Cole JC, Nipper ML, et al. Computed tomography and ultrasonography in the diagnosis of appendicitis: when are they indicated. Arch Surg 2001;136(6):670-5.

10. Rao PM, Rhea JT, Novelline, et al. Effect of computed tomography of the appendix on treatment of patients and use of hospital resources. N Engl J Med 1998;338(3): 141-6. 